\section{Nesiritide and clinically relevant outcomes in cardiac surgery: a meta-analysis of randomized studies}

\author{
GIULIA MAJ • GIOVANNI LANDONI • GIUSEPPE BIONDI-ZOCCAI • \\ ELENA BIGNAMI • LUCA CABRINI • LUCA BURATTI • \\ MASSIMILIANO GRECO • MASSIMO ZAMBON • ALBERTO ZANGRILLO
}

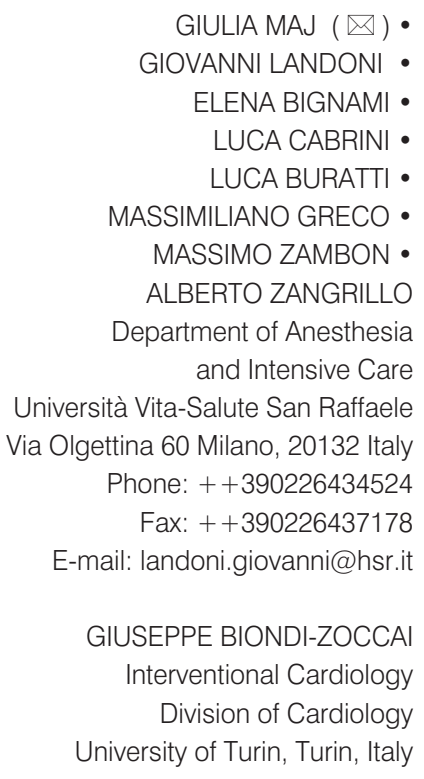

GIULIA MAJ $(\triangle) \cdot$ GIOVANNI LANDONI • ELENA BIGNAMI • LUCA CABRINI • LUCA BURATTI • MASSIMILIANO GRECO • MASSIMO ZAMBON • ALBERTO ZANGRILLO Department of Anesthesia and Intensive Care Università Vita-Salute San Raffaele Via Olgettina 60 Milano, 20132 Italy Phone: ++390226434524 Fax: ++390226437178 E-mail: landoni.giovanni@hsr.it

\author{
GIUSEPPE BIONDI-ZOCCAI \\ Interventional Cardiology \\ Division of Cardiology \\ University of Turin, Turin, Italy
}

\begin{abstract}
B-type natriuretic peptide is a cardiac hormone that relaxes vascular smooth muscle and causes arterial dilatation. Nesiritide has been associated with increased urine output; reduced diuretic requirements; and suppression of aldosterone, endothelin, and norepinephrine. We have independently conducted the first systematic review and meta-analysis of randomized trials to determine the impact of nesiritide on renal replacement therapy and death in patients undergoing cardiac surgery. We performed a meta-analysis of 6 randomized controlled studies including 560 patients (280 receiving nesiritide and 280 assigned to the control group). Two unblinded reviewers selected randomized trials studying nesiritide in patients undergoing cardiac surgery. Nesiritide doses ranged from $0.005 \mathrm{mcg} / \mathrm{kg} / \mathrm{min}$ to $0.01 \mathrm{mcg} / \mathrm{kg} / \mathrm{min}$. Nesiritide did not reduce postoperative creatinine peak values: -0.16 [-0.42, 0.10], $p$ for effect $=0.23, p$ for heterogeneity $<0.01,12=90.5 \%$ ) or the need for renal replacement therapy (1/177 in the nesiritide group vs 4/176 in the control group OR 0.39 [0.07, 2.06], $p$ for effect $=0.27, p$ for heterogeneity $=0.70,12=0 \%)$. We observed an interesting trend toward a reduction in mortality in the nesiritide group:13/280 (4.6\%) vs 22/280 (7.8\%) OR 0.57 [0.28, 1.15], p for effect $=0.12$, p for heterogeneity $=0.43,12=0 \%$. Nesiritide did not reduce time of mechanical ventilation -8.77 hours [-21.42, 3.88], $p=0.17$, length of hospital stay -2.67 days [-6.50, 1.16], $p=0.17$ or intensive care unit (ICU) stay -0.94 days [-2.83, 0.95], $p=0.33$. In conclusion, further randomized controlled trials are needed to support the hypothesis that nesiritide improves clinically relevant outcomes in cardiac surgery.
\end{abstract}

Key words: Nesiritide, meta-analysis, cardiac surgery, renal replacement therapy, mortality.

\section{Introduction}

Acute renal failure is associated with significant morbidity and mortality rates. $(1,2)$ Need for dialysis is an independent risk factor for early mortality after complicated cardiac surgery. $(3,4)$ The pathogenesis of postoperative acute renal failure is believed to be predominantly a consequence of renal hypoper- fusion and ischemia, particularly of the renal medulla. (5)

Several therapeutic strategies for preserving renal function after cardiac surgery have been investigated, (6-12) but to date none have been proven effective.

Brain natriuretic peptide (BNP) is currently being investigated in the perioperative management of cardiac surgery patients and may be especially beneficial for patients with ventricular dysfunction, pulmonary hypertension, or renal dysfunction. Measured BNP levels can be used to predict postoperative complications and the risk of further cardiac events in cardiac surgery. (13-15)

Nesiritide is a recombinant B-type natriuretic peptide that is structurally identical to the endogenous hormone produced by the ventricle in response to increased wall stress, hypertrophy and volume overload. Nesiritide causes vasodilatation and may influence renal blood flow and natriuresis. It produces 
Table 1. features of included papers.

\begin{tabular}{lllll}
\hline Author & Year & Paper & Surgical procedure & Multicentric \\
\hline Mentzer RMJ[22] & 2007 & JACC & CABG + mitral surgery & yes \\
Chen HH[23] & 2007 & Circulation & CABG+ valvular \\
+ ascending aorta & no \\
Sezai A [24] & 2006 & Circ J & CABG & no \\
Sezai A[25] & 2007 & Circ J & CABG & no \\
Hayashida N[26] & 2000 & Ann Thor Surg & mitral surgery & no \\
Brackbill ML[27] & 2007 & Ann Pharmacotherapy & CABG & no \\
\hline
\end{tabular}

Table 2. Risk of bias assessment of included studies (Jadad Score).

\begin{tabular}{|c|c|c|c|c|c|c|}
\hline TRIAL & $\begin{array}{l}\text { 1. Was } \\
\text { the study } \\
\text { described as } \\
\text { randomized? }\end{array}$ & $\begin{array}{l}\text { additional/ } \\
\text { deduct point }\end{array}$ & $\begin{array}{l}\text { 2. Was } \\
\text { the study } \\
\text { described as } \\
\text { double blind? }\end{array}$ & $\begin{array}{l}\text { additional/ } \\
\text { deduct point }\end{array}$ & $\begin{array}{l}\text { 3. Was there } \\
\text { a description } \\
\text { of withdraw- } \\
\text { als and drop- } \\
\text { outs? }\end{array}$ & $\begin{array}{l}\text { FINAL } \\
\text { SCORE }\end{array}$ \\
\hline $\begin{array}{l}\text { Mentzer RMJ, } \\
2007[22]\end{array}$ & 1 & - & 1 & - & 1 & 3 \\
\hline Chen HH, 2007[23] & 1 & - & 1 & - & 1 & 3 \\
\hline Sezai A , 2006 ${ }^{[24]}$ & 1 & - & 1 & - & 1 & 3 \\
\hline Sezai A, 2007 & 1 & - & 0 & - & 1 & 3 \\
\hline $\begin{array}{l}\text { Hayashida N, } \\
2000[26]\end{array}$ & 1 & 1 & 0 & - & 1 & 2 \\
\hline $\begin{array}{l}\text { Brackbill ML, } \\
2007[27]\end{array}$ & 1 & - & 0 & - & 1 & 3 \\
\hline
\end{tabular}

Table 3. Preoperatory creatinine values and Nesiritide Perfusion values.

\begin{tabular}{lllll}
\hline Author & Preop Crea Nesiritide & Preop Crea Control & $\begin{array}{l}\text { Nesiritide Bolus } \\
(\mathrm{mcg} / \mathrm{Kg})\end{array}$ & $\begin{array}{l}\text { Nesiritide Perfusion } \\
(\mathrm{mcg} / \mathrm{kg} / \mathrm{min})\end{array}$ \\
\hline Mentzer RMJ, 2007[22] & $1,07+0,40$ & no & 0.01 \\
Chen HH, 2007[23] & $1,7+0,5$ & $1,11+0,44$ & 0.005 \\
Sezai A, 2006[24] & - & $1,7+0,7$ & no & 0.02 \\
Sezai A, 2007[25] & - & - & no & 0.01 \\
Hayashida N, 2000[26] & - & - & no & 0.05 \\
Brackbill ML, 2007[27] & $1,0+0,3$ & - & no & 0.01 \\
\hline
\end{tabular}


dose-related reductions in pulmonary capillary wedge pressure (preload), right atrial pressure and systemic vascular resistance and indirectly leads to increases in stroke volume and cardiac output. (16) Nesiritide is currently approved in the US for the treatment of acute decompensated heart failure.

Numerous, apparently positive but inconclusive reports, targeted to surrogateend-points, haverecentlyappeared in the literature on the use of nesiritide in subjects undergoing cardiac surgery. Nesiritide may even be associated with an increased risk of death when used for the treatment of patients with acutely decompensated heart failure. (17) To address the question whether nesiritide might influence patients' outcome after cardiac surgery, we have independently conducted an updated systematic review and meta-analysis from existing trials to determine, for the first time, the impact of nesiritide on the perioperative need for renal replacement therapy and its impact on death in patients undergoing cardiac surgery.

\section{Materials and methods}

Search Strategy Pertinent studies were independently searched in BioMedCentral, CENTRAL, and PubMed (updated June 15,2008$)$ by two trained investigators. The full PubMed search strategy, including the key-word, nesiritide, was developed according to Biondi-Zoccai et al. (18) and is available in the appendix. Recent (2006-2008) conference proceedings, from the International Anesthesia Research Society, American Heart Association, American College of Cardiology, American Society of Anesthesiology and European Society of Cardiology, were hand searched. In addition, we employed backward snowballing (ie scanning of references of retrieved articles and pertinent reviews) and contacted international experts for further studies. No language restriction was enforced, and non-English-language articles were translated when appropriate.

References obtained from database and literature searches were first independently examined at the title/abstract level by several investigators with diver- gences resolved by consensus, and then, if potentially pertinent, retrieved as complete articles.

The following inclusion criteria were employed for potentially relevant studies: a) random allocation to treatment, b) comparison of nesiritide versus control or other treatment, c) patients undergoing adult cardiac surgery.

The exclusion criteria were: a) nonparallel design (ie cross-over) randomized trials, b) duplicate publications (in this case only the article reporting the longest follow-up was abstracted), c) non-human experimental studies, and e) no outcome data.

Two investigators independently assessed compliance with selection criteria and selected studies for the final analysis, with divergences finally resolved by consensus (table 1).

Baseline and outcome data were independently abstracted by several investigators with divergences resolved by consensus. Specifically, we extracted study design (including patient selection and randomization), population, clinical setting, the number of patients randomized, patients' characteristics (preoperative creatinine), serum peak creatinine values, renal replacement therapy, adverse events, mechanical ventilation, intensive care unit (ICU) stay, length of hospital stay, death. At least two separate attempts at contacting original authors were made in case of missing data.

The primary end-point of our analysis was in-hospital mortality. The co-primary endpoint was the number of patients progressing to acute kidney injury (AKI) requiring at least one episode of renal replacement therapy. Secondary endpoints included peak serum creatinine levels, mechanical ventilation and the duration of ICU and hospital stay.

The internal validity and risk of bias of included trials was appraised according to the Jidad score and by completing a risk of bias table. This was performed by two independent reviewers, with divergences resolved by consensus (table 2). Two independent and experienced reviewers also appraised study quality, with divergences resolved by consensus. Binary outcomes from individual stud- ies were analyzed in order to compute individual relative risks (RR) with pertinent 95\% confidence intervals $(\mathrm{Cl})$, and a pooled summary effect estimate was calculated by means of a fixed effects model, except in the case of at least moderate $(50 \%)$ statistical inconsistency $\left(\mathrm{l}^{2}\right)$ when a random effect model was used. (19)

We assessed the robustness of findings from the primary analysis through a series of sensitivity analyses, including random effects model, and by withdrawing one study at a time. Statistical heterogeneity and inconsistency was measured using, respectively, Cochran $Q$ tests and $\mathrm{I}^{2}$. (20)

According to Higgings et al. $1^{2}$ values around $25 \%, 50 \%$, and $75 \%$ were considered representing respectively low, moderate and severe statistical inconsistency. The risk of small study bias (including publication bias) was assessed by visual inspection of funnel plots. Statistical significance was set at the two-tailed 0.05 level for hypothesis testing and at 0.10 for heterogeneity testing. Unadjusted $P$ values are reported throughout. Computations were performed with SPSS 11.0 (SPSS, Chicago, IL, USA), and RevMan 4.2 (a freeware available from The Cochrane Collaboration). (21)

This study was performed in compliance with The Cochrane Collaboration and the Quality of Reporting of MetaAnalyses (QUOROM) guidelines.

\section{Results}

Database searches, snowballing and contacts with experts yielded a total of 9 citations. Excluding 3 non pertinent titles or abstracts, we retrieved six studies in complete form and assessed them according to the selection criteria, (22-27) which were included in the final analysis after the correspondent authors confirmed that there was no overlapping and/or duplicate publication. Five of these 6 studies were identified through database searches, while snowballing identified the sixth study. (24) Contact with experts and conference proceedings did not identify any further studies. 
Study Characteristics The six randomized controlled studies included 560 patients (280 to nesiritide and 280 to the control group). All studies were performed in adult patients undergoing cardiac surgery (table 1).

All studies were of relatively high quality, with a low or moderate risk of underlying bias (table 2). One study employed a multicenter design. (22) All studies reported on mortality, while four of six studies reported data on renal replacement therapy, $(23-25,27)$ postoperative serum creatinine peak $(22,24,25,27)$ and ICU stay. (22,25-27) Three studies reported data on length of hospital stay $(22,25,27)$ and mechanical ventilation. $(22,25,26)$

Two studies used nesiritide $(24,25)$ infusion for 12 hours, one study for six hours (26) and other studies for at least 24 hours. $(22,23,27)$ Nesiritide doses ranged from $0.005 \mathrm{mcg} / \mathrm{kg} / \mathrm{min}$ to 0.05 $\mathrm{mcg} / \mathrm{kg} / \mathrm{min}$. Brackbill et al. (27) used 2 $\mathrm{mcg} / \mathrm{Kg}$ of nesiritide as bolus (table 3).

Quantitative Data Synthesis Analysis showed that, in comparison to control treatment, nesiritide was not associated with clinically relevant benefits according to our major end points. Specifically, nesiritide did not reduce postoperative creatinine peak values: $-0.16[-0.42$, $0.10], p$ for effect $=0.23, p$ for heterogeneity<0.001, $\left.\right|^{2}=90.5 \%$ ) (figure 1 ) Nesiritide also did not reduce the need for renal replacement therapy $1 / 177$ in the nesiritide group vs 4/176 in the control group OR 0.39 [0.07, 2.06], p for effect $=0.27$, $p$ for heterogeneity $=0.70$, $\mathrm{I}^{2}=0 \%$ ) (figure 2). There was an interesting trend toward a reduction in mortality: $13 / 280(4.6 \%)$ in the nesiritide group vs $22 / 280(7.8 \%)$ in the control group OR $0.57[0.28,1.15]$, p for effect $=0.12, p$ for heterogeneity $=0.43,1^{2}=0 \%$ ) (figure3). Finally, nesiritide did not reduce time of mechanical ventilation -8.77 hours $[-21.42,3.88], p$ for effect $=0.17, p$ for heterogeneity $=0.05, l^{2}=67.5 \%$, (figure 4) length of hospital stay -2.67 days $[-6.50,1.16], p$ for effect $=0.17, p$ for heterogeneity $<0.001 \mathrm{l}^{2}=85.6 \%$, (figure 5) and ICU stay -0.94 days [-2.83, 0.95], $p$ for effect $=0.33$, $p$ for heterogeneity $=0.10,\left.\right|^{2}=51.5 \%$ (figure 6 ). Hypotension was reported by only Mentzer et al.

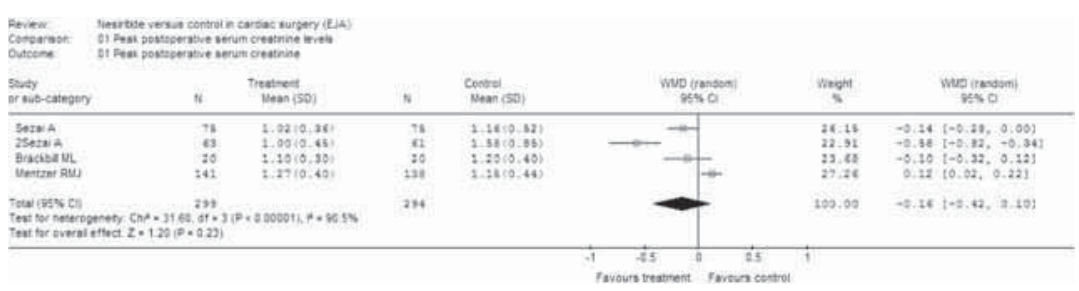

Figure 1. Individual and pooled estimates for peak postoperative serum creatinine $(\mathrm{mg} / \mathrm{dl})$.

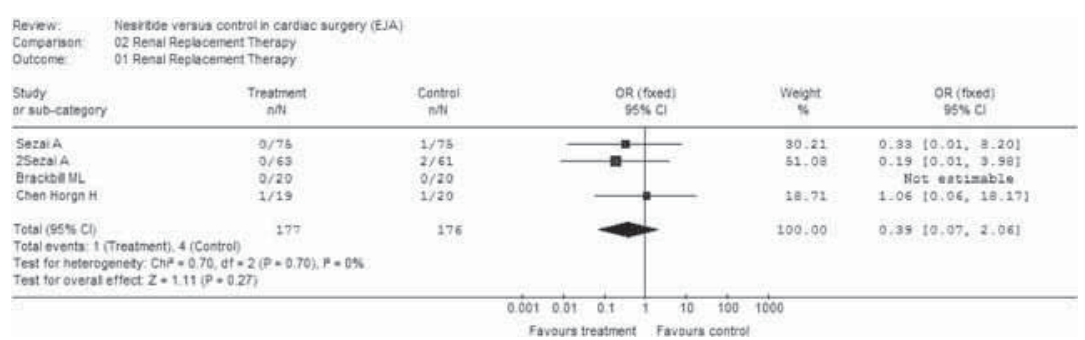

Figure 2. Individual and pooled estimates for the risk for renal replacement therapy.

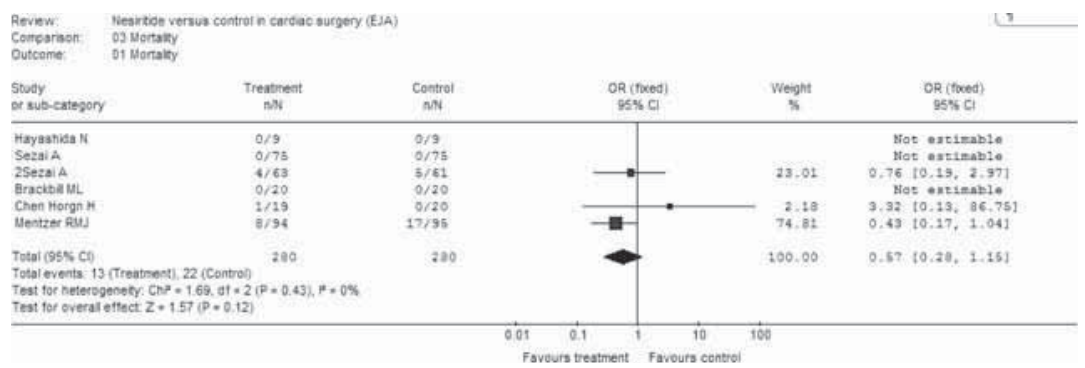

Figure 3. Individual and pooled estimates for the risk for mortality.

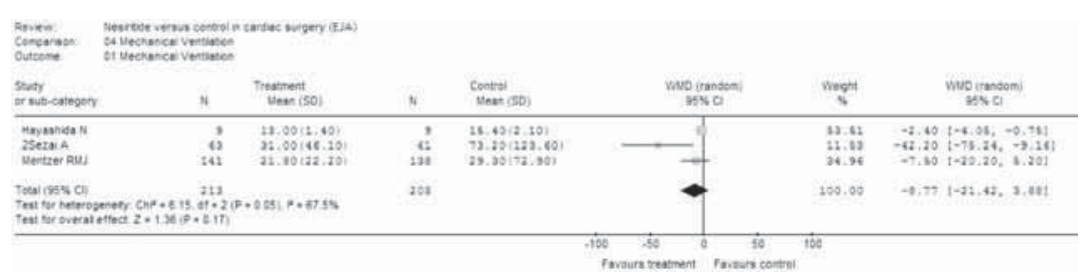

Figure 4. Individual and pooled estimates for time on mechanical ventilation (hours).

(22) (one in the nesiritide group versus two in the control group). No significant side effect or adverse event was reported by the uthors.

\section{Discussion}

The most important result of this metaanalysis of six randomized controlled studies is that, in spite of promising initial reports on the beneficial effects of nesiritide, there is still no evidence of improvement in clinically relevant outcomes when using this drug. In particular, nesiritide does not reduce the need for renal replacement therapy, ICU stay, the length of hospital stay and the time of mechanical ventilation. Although no significant association between nesirit- 
ide and mortality has been found in our study, a trend suggesting lower mortality rates for patients treated with nesiritide was suggested. The $50 \%$ reduction in mortality observed in this meta-analysis, although statistically significant, could be of interest for further studies. Unfortunately, to demonstrate a reduction in mortality from $7.8-4.6$ researchers have to plan a large trial of at least 2000 patients. No systematic review regarding the efficacy of nesiritide in the specific setting of cardiac surgery has been published so far. This review is unique in looking at a meta analysis of neseritide in the post operative adult cardiac patient.

Natriuretic peptides belong to a family of small proteins that play a major role in modulation of natriuresis, diuresis and vasodilatation. They counteract the activity of the renin-angiotensin-aldosterone system. They are also involved in the regulation of homeostasis, fat metabolism and long bone growth. Natriuretic peptides share a common 17-amino-acid structure and have actions that are targeted at protecting the cardiovascular system from the effect of volume overload. Secretion of the peptides is stimulated by atrial and ventricular distension, increased blood pressure, hypoxia or renal dysfunction. (16) Natriuretic peptides are systemic and renal vasodilators that also inhibit renal tubular sodium reabsorbtion and renin-angiotensin-aldosterone axis activation. (28)

Nesiritide is the synthetic natriuretic peptide (recombinant BNP) which is approved for treatment of symptomatic acute decompensated heart failure. Nesiritide is a 32 amino acid peptide, similar to the naturally occurring BNP and when administred intravenously fits a two-compartment model with a rapid distribution half-life of 2 minutes. The haemodynamic effects of nesiritide, mainly consisting in the lowering of pulmonary capillary wedge pressure, and systolic blood pressure, are observed in the first 15 minutes of an infusion. (29) In studies in which patients received standard congestive heart failure therapy (diuretics, dopamine), nesiritide

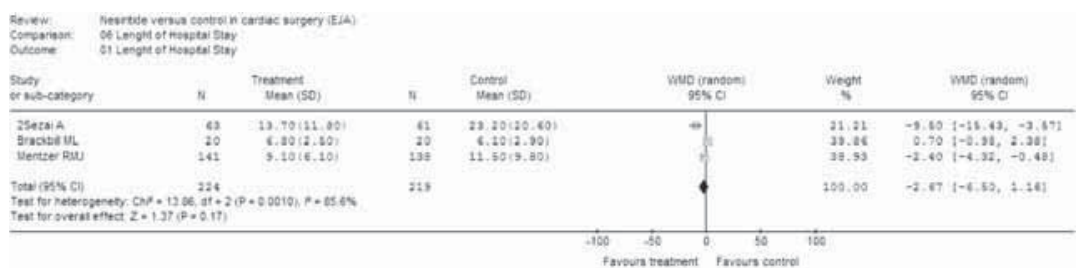

Figure 5. Individual and pooled estimates for length of hospital stay (days).

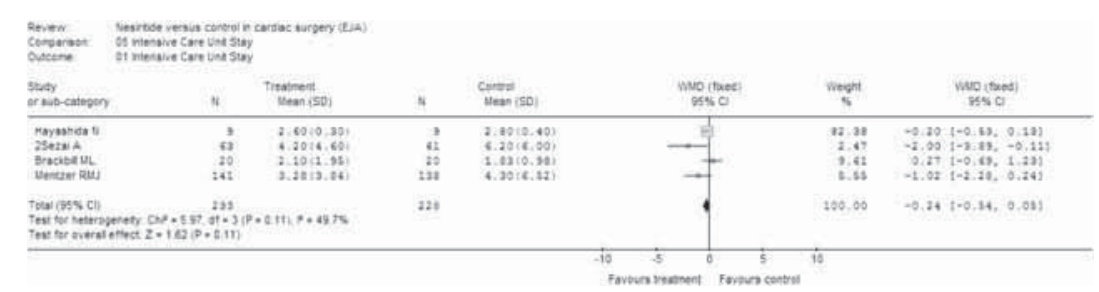

Figure 6. Individual and pooled estimates for intensive care unit (ICU) stay (days).

therapy lowered pulmonary capillary occlusion pressure and resolve dyspnea more rapidly than nitroglycerin and placebo. (30) Nesiritide showed a dose-dependent arterial and venous vasodilatation effect, mediated by the activation of cyclic guanosine 3-5 monophosphate-coupled receptor NPR-A which is present in the endothelium. (31) During nesiritide infusions, plasma aldosterone levels decrease, combined with increased urine output and sodium excretion. (32) Nesiritide improves symptoms in patients with acutely decompensated heart failure compared with placebo and appears to be safer than dobutamine. Its short term safety, relative to standard diuretic and vasodilator therapies, is less clear. Recently, a meta-analysis of outcome data from trials on acute decompensated heart patients generated some controversy, (17) and further trials are needed to discern the effects of nesiritide therapy on renal function. Wang DJ et al. demonstred that nesiritide infusion in decompensated heart failure patients does not improve renal function. (33)

BNP plasma levels can also be used as a marker of the presence of acute heart failure. It has been demonstrated that BNP levels rise when ventricle walls are dilated during acute heart failure. Elevated levels of BNP are not only pres- ent during primary acute heart failure but may be related to secondary right heart failure in the case of pulmonary embolism, severe lung disease or an exacerbation of established systolic dysfunction resulting from other causes.

The NAPA trial was a multicenter randomized, double-blind, placebo-controlled trial of nesiritide versus placebo in 303 patients with chronic left ventricular dysfunction undergoing cardiac surgery. This study revealed that nesiritide infusion has a favorable shortterm effect on renal function. Patients receiving nesiritide had greater urine output, lower peak increase in serum creatinine levels in the immediate postoperative period compared with patients receiving placebo. (22) Chen et al. demonstrated that perioperative administration of low dose nesiritide is biologically active and decreases plasma cystatin in patients with renal insufficiency undergoing cardiopulmonary bypass cardiac surgery. (23) Intraoperative administration of nesiritide had potent effects on natriuresis and systemic vasodilatation by elevating cyclic guanosine monophosphate levels. Nesiritide can be useful for the management of haemodinamics and water-sodium retention after cardiopulmonary bypass. (26)

Limitations. We analyzed data from six 
studies which have different inclusion criteria. Therefore, patients included might have differed significantly in baseline clinical characteristics. Different clinical conditions (such as renal dysfunction, heart failure, valvular defects), therapeutic protocols, and surgical scenarios may affect the effectiveness of nesiritide.

Conclusions. Our meta-analysis dem- onstrated that nesiritide is not yet an established method for the prevention of acute renal failure and mortality in cardiac surgery. Further randomized controlled studies are warranted.

\section{APPENDIX}

PubMed search strategy according to Biondi-Zoccai et al. (18)

(nesiritide) AND (operatin* OR operativ* OR operation* OR interven* OR surger* OR surgic*) AND (randomized controlled trial[pt] OR controlled clinical trial[pt] OR randomized controlled trials[mh] OR random allocation[mh] OR double-blind method[mh] OR single-blind

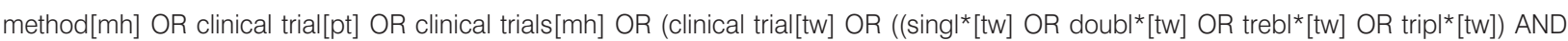
(mask*[tw] OR blind[tw])) OR (latin square[tw]) OR placebos[mh] OR placebo*[tw] OR random*[tw] OR research design[mh:noexp] OR comparative study[tw] OR follow-up studies[mh] OR prospective studies [mh] OR cross-over studies[mh] OR control*[tw] OR prospectiv*[tw] OR volunteer*[tw]) NOT (animal[mh] NOT human[mh]) NOT (comment[pt] OR editorial[pt] OR meta-analysis[pt] OR practice-guideline[pt] OR review[pt]))

\section{REFERENCES}

1. Biancofiore G. Postoperative renal dysfunction. Have we emerged from the labyrinth? Minerva Anestesiol 2010;76:239-40

2. Zarbock A, Singbartl K, Kellum JA. Evidence-based renal replacement therapy for acute kidney injury. Minerva Anestesiol 2009;75:135-9.

3. Bove T, Calabrò MG, Landoni G, Aletti G, Marino G, Crescenzi G, et al. The incidence and risk of acute renal failure after cardiac surgery. J Cardiothorac Vasc Anesth 2004;18:442-5.

4. Landoni G, Bove T, Crivellari M, Poli D, Fochi O, Marchetti C, et al. Acute renal failure after isolated CABG surgery: six years of experience. Minerva Anestesiol 2007;73:559-65.

5. Chertow GM, Levy EM, Hemmermeister KE, Grove F, Daley J. Indipendent association between acute renal failure and mortality following surgery. Am J Med 1998;104:343-8.

6. Ranucci M, De Benedetti D, Bianchini C, Castelvecchio S, Ballotta A, Frigiola A, et al. Effects of fenoldopam infusion in complex cardiac surgical operations: A prospective, randomized, double-blind, placebo-controlled study. Minerva Anestesiol 2010;76:249-59.

7. Karajala V, Mansour W, Kellum JA. Diuretics in acute kidney injury. Minerva Anestesiol 2009;75:251-7.

8. Landoni G, Mizzi A, Biondi-Zoccai G, Bignami E, Prati P, Ajello V, et al. Levosimendan reduces mortality in critically ill patients. A metaanalysis of randomized controlled studies. Minerva Anestesiol 2010;76:276-86.

9. Meco M, Cirri S. Effects of fenoldopam mesylate on central hemodynamics and renal flow in patients undergoing cardiac surgery: color Doppler echocardiographic. J Cardiothorac and Vasc Anesth 2010;24:58-62.

10. Bignami E, Landoni G, Biondi-Zoccai GG, Boroli F, Messina M, Dedola E, et al. Epidural analgesia improves outcome in cardiac surgery: a meta-analysis of randomized controlled trials. J Cardiothorac Vasc Anesth 2010;24:586-97.

11. Huffmyer JL, Mauermann WJ, Thiele RH, Ma JZ, Nemergut EC. Preoperative statin administration is associated with lower mortality and decreased need for postoperative hemodialysis in patients undergoing coronary artery bypass graft surgery. J Cardiothorac Vasc Anesth 2009;23:468-73.

12. Augoustides JG, Patel P. Recent advances in perioperative medicine: highlights from the literature for the cardiothoracic and vascular anesthesiologist. J Cardiothorac Vasc Anesth 2009;23:430-6.

13. Nozohoor S, Nilsson J, Lührs C, Roijer A, Algotsson L, Sjögren J. B-type natriuretic peptide as a predictor of postoperative heart failure after aortic valve replacement. J Cardiothorac Vasc Anesth 2009;23:161-5.

14. Crescenzi G, Landoni G, Bignami E, Belloni I, Biselli C, Rosica C, et al. N-terminal B-natriuretic Peptide after coronary artery bypass graft surgery. J Cardiothorac Vasc Anesth 2009;23:147-50.

15. Noveanu M, Hartwiger S, Mueller C. What anesthesiologists should know about B-type natriuretic peptide. Minerva Anestesiol 2009;75:698-702. 
16. Nakao K, Ogawa Y, Suga S, Imura H. Molecular biology and biochemistry of the natriuretic peptide system II: natriuretic peptide receptors. J Hypertens 1992;10:1111-4.

17. Sackner-Bernstein JD, Kowalski M, Fox M, Aaronson K. Short-term risk of death after treatment with Nesiritide for decompensated heart failure. A pooled analysis of randomized controlled trials. JAMA 2005;293:1900-5.

18. Biondi-Zoccai GG, Agostoni P, Abbate A, Testa L, Burzotta T. A simple hint to improve Robinson and Dickersin's highly sensitive PubMed search strategy for controlled clinical trials. Int J Epidemiol 2005;34:224-5.

19. Fleiss JL. The statistical basis of meta-analysis. Stat Methods Med Res 1993;2:121-45.

20. Higgins JP, Thompson SG, Deeks JJ, Altman DG. Measuring inconsistency in meta-analyses. BMJ 2003;327:557-60.

21. Higgins JPT, Green S. The Cochrane Handbook for Systematic Reviews of Interventions 4.2.5. Available at: http://www.cochrane.org/ resources/handbook/hbook.htm (accessed 10 April 2007)

22. Mentzer RM Jr, Oz MC, Sladen RN, Graeve AH, Hebeler RF Jr, Luber JM Jr, et al. NAPA Investigators. Effects of perioperative nesiritide in patients with left ventricular dysfunction undergoing cardiac surgery: the NAPA Trial. J Am Coll Cardiol 2007;49:716-26.

23. Chen HH, Sundt TM, Cook DJ, Heublein DM, Burnett JC Jr. Low dose nesiritide and the preservation of renal function in patients with renal dysfunction undergoing cardiopulmonary-bypass surgery: a double-blind placebo-controlled pilot study. Circulation 2007;116:134-8.

24. Sezai A, Hata M, Wakui S, Shiono M, Negishi N, Kasamaki Y, et al. Efficacy of low-dose continuous infusion of alpha-human atrial natriuretic peptide (hANP) during cardiac surgery: possibility of postoperative left ventricular remodeling effect. Circ J 2006;70:1426-31.

25. Sezai A, Hata M, Wakui S, Niino T, Takayama T, Hirayama A, et al. Efficacy of continuous low-dose hANP administration in patients undergoing emergent coronary artery bypass grafting for acute coronary syndrome. Circ J 2007;71:1401-7.

26. Hayashida N, Chihara S, Kashikie H, Tayama E, Yokose S, Akasu K, et al. Effects of intraoperative administration of atrial natriuretic peptide. Ann Thorac Surg 2000;70:1319-26.

27. Brackbill ML, Stam MD, Schuller-Williams RV, Dhavle AA. Perioperative nesiritide versus milrinone in high-risk coronary artery bypass graft patients. Ann Pharmacother 2007;41:427-32.

28. Murray P. Brain natriuretic peptide therapy to prevent acute kidney injury after cardiac surgery. Am J Kidney Dis. 2008;51:5-9.

29. De Denus S, Pharand C, Williamson D. Brain natriuretic peptide in the management of heart failure: the versatile neurohormone. Chest 2004;125:652-68

30. Publication Commettee for the VMAC investigators. Intravenous nesiritide vs. nitroglycerin for treatment of decompensated congestive heart failure: a randomized controlled trial. JAMA 2002;287:1531-40.

31. Zineh I, Schonfield RS, Johnson JA. The evolving role of nesiritide in advanced or decompensated heart failure. Pharmacotherapy 2003;23:1266-80

32. Aronson D, Burger AJ. Intravenous nesiritide (human B-type natriuretic peptide) reduces plasma endothelin-1 levels in patients with decompensated congestive heart failure. Am J Cardiol 2002;90:435-8.

33. Wang DJ, Dowling TC, Meadows D, Ayala T, Marshall J, Minshall S et al. Nesiritide does not improve renal function in patients with chronic heart failure and worsening serum creatinine. Circulation. 2004 Sep 21;110:1620-5. 